\title{
HISTORYCZNE NAZEWNICTWO OSOBOWE PODLASKIEGO RODU KIERSNOWSKICH W XVI-XVII STULECIU
}

\author{
Piotr ZŁotKowski \\ Uniwersytet Marii Curie-Skłodowskiej w Lublinie
}

\begin{abstract}
HISTORICAL PERSONAL NAMES OF THE KIERSNOWSKI FAMILY FROM THE POD-

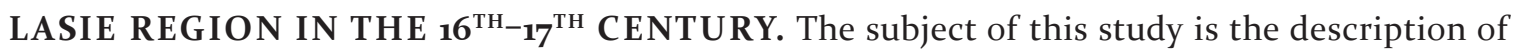
the historical personal names of the Kiersnowski family from the Podlasie region. The Kiersnowski surname, first names, nicknames and patronymic formations identifying members of this family were subjected to anthroponymous analysis. The chronological scope of research covers the span of two centuries, including a period from the beginning of the $16^{\text {th }}$ to the end of the $17^{\text {th }}$ century. The following selection is dictated by a fact that many historical sources from this period have survived. In addition, some processes that brought about significant changes in the local anthroponymous microsystem can be observed.
\end{abstract}

Keywords: Kiersnowski family, Kiersnowo, Podlasie region, anthroponymy

Tematem niniejszego opracowania jest charakterystyka historycznego nazewnictwa osobowego podlaskiego rodu Kiersnowskich. Na jego potrzeby poddano analizie antroponimicznej nazwisko Kiersnowski, imiona, przezwiska, przydomki oraz formacje patronimiczne używane przez członków tej rodziny. Zakres chronologiczny rozważań obejmuje okres od początku XVI do końca XVII wieku, czyli dwa stulecia. Wybór ten jest podyktowany stosunkowo dobrze zachowaną bazą materiałową z tego czasu. Ponadto, miały wtedy miejsce procesy, które spowodowały istotne zmiany w lokalnym mikrosystemie antroponimicznym.

Aby właściwie zinterpretować owe przemiany nazewnicze należy je umieścić w odpowiednim kontekście kulturowo-historycznym. W tym celu konieczne jest przynajmniej pobieżne zapoznanie się z dziejami rodu Kiersnowskich. Gniazdem rodziny jest miejscowość o nazwie Kiersnowo, położona w dawnym województwie podlaskim, w ziemi i powiecie brańskim. Mimo, iż obszar ten jest już stosunkowo dobrze zbadany pod względem historycznym, brakuje monografii, w której ujęto by całościowo dotychczasowe wyniki 
badań. Nieco lepiej wygląda to od strony onomastycznej. Zostały już opracowane tutejsze toponimy i mikrotoponimy oraz historyczne nazewnictwo osobowe warstwy chłopskiej i mieszczańskiej (Kondratiuk 1974, Tichoniuk 1986, Tichoniuk 1988, Zlotkowski 2017a). Nie ukazała się jednak monografia o historycznych nazwach osobowych miejscowej szlachty.

Wieś Kiersnowo jest położona nieopodal miasta Brańska. W przeszłości był to teren, na którym ścierały się prądy osadnicze: zachodnio- i wschodniosłowiański. Obecnie ten ostatni żywioł jest znacznie słabszy niż przed wiekami. Powodem tego był proces polonizacji tutejszej ludności, który objął wszystkie warstwy społeczne, począwszy od szlachty, poprzez mieszczaństwo, aż po chłopów. Przemiany etniczno-konfesyjne miały swoją wewnętrzną dynamikę i były zależne od różnych czynników, których omówienie wybiega poza ramy tego artykułu.

Odtworzenie genezy powstania i początków miejscowości położonych na badanym obszarze nie zawsze jest możliwe. W tym konkretnym przypadku jest inaczej. Dysponujemy odpisem dokumentu z 1586 roku, który rzuca wiele światła na tę kwestię. W tymże roku w grodzie brańskim stawili się Mikołaj syn niegdyś Wawrzyńca, Benedykt i Łukasz, synowie niegdyś Stefana oraz Iwan syn nieżyjącego Pawła z Kiersnowa i zeznali, iż są krewnymi Fedora, który wraz z braćmi dziedziczy majętność Skoki, położoną w Wielkim Księstwie Litewskim, niedaleko Brześcia. Z zachowanego manuskryptu wynika, że przodkami wymienionych szlachciców byli trzej bracia: Ihat, Jesio i Bohdan, którzy w czasach panowania króla Aleksandra Jagiellończyka, a więc przed 1506 rokiem, posiadali dziedziczną wieś Skoki w powiecie brzeskim oraz miejscowość Kiersnowo w powiecie bielskim. Z treści dokumentu można również wywnioskować, że potomstwo Bohdana osiadło w pierwszej miejscowości, a następcy Ihnata i Jesia dziedziczyli w drugiej. ${ }^{1}$ Powyższy przekaz potwierdzają późniejsze o ponad dwie dekady dane rejestru pospolitego ruszenia szlachty WKL z 1528 roku, w którym wymienieni są: Jesko, Wasko i Oleszko, synowie Ihnata oraz Misko i Ostasz, synowie Jeska. ${ }^{2}$ Pewne trudności nastręcza określenie przynależności herbowej rodu Kiersnowskich. We wspomnianym już dokumencie z 1586 roku przypisany im jest herb Cholewa, natomiast w XIX-wiecznym herbarzu podlaskiego archiwisty i heraldyka Ignacego Kapicy rodzinę tę odnotowano z herbem Pobóg. ${ }^{3}$

Nie budzi natomiast wątpliwości fakt zasiedlenia Kiersnowa przez szlachtę pochodzenia ruskiego, a używając dzisiejszej terminologii, wschodniosłowiańskiego. Niektórzy historycy, m. in. Jerzy Wiśniewski, wyrażali pogląd, że pierwotnie był to ród bojarski, tak

1 ZZG 18, s. 97-99.

2 RIB 33, 182.

3 ZZG 18, s. 98; HerKap 170. 
jak np. osiedleni w pobliżu Poletyłowie, czy Szpakowie (Wisniewski 1977: 17). W zgromadzonym materiale historycznym brak jednoznacznych przesłanek na potwierdzenie tej hipotezy. W wymienionym już popisie wojskowym z 1528 roku Kiersnowscy odnotowani są jako pełnoprawni członkowie warstwy szlacheckiej.

Nazwisko Kiersnowski pochodzi od nazwy miejscowej Kiersnowo. Utworzono je według dobrze znanego w antroponimii schematu, polegającego na tym, że do podstawy w postaci toponimu dodawano formant -ski (pochodzenia przymiotnikowego). Toponim Kiersnowo, zdaniem onomasty Michała Kondratiuka, należy łączyć z analogicznymi nazwami miejscowymi i rzecznymi na Litwie, np. wsie Kirsnakaviznos, Kirsneles, Kirsnokiškeles, rzeki Kirsná, Kiršnóupis. Badacz podaje również, że nazwa rzeki Kirsná pochodzi od staropruskiego przymiotnika kirsnan 'czarny' (Kondratiuk 1974: 83-84). Można się zastanawić nad słusznością owej hipotezy, jednak wypada ją przyjąć, ponieważ dotychczas nie przedstawiono bardziej przekonywującego wyjaśnienia etymologii tej nazwy. Należy również dodać, że przywołany już Jerzy Wiśniewski, łączył nazwę wsi z emigrantami z części Jaćwieży zwanej Kirsnowiq̨ (Wisniewski 1964: 131).

Wspomniano już, że w interesującej nas miejscowości osiadła szlachta pochodzenia ruskiego. Wskazują na to niezlatynizowane postaci imion jej pierwszych mieszańców: Bohdan, Ihnat, Iwan, Jesio, Misko, Ostasz, Oleszko, Wasko. Niektóre z nich stanowią derywaty o charakterze hipokorystyczno-deminutywnym, utworzone poprzez dodanie do podstawy formantu zawierającego spółgłoskę -k-. Można przypuszczać, że pierwotnie wszyscy Kiersnowscy byli wyznawcami religii prawosławnej. Pośrednio świadczy o tym fakt, ze jeden z Kiersnowskich - Kacper, według wzmianki z 1599 roku, został pochowany w cerkwi brańskiej. ${ }^{4}$ Dotychczasowe badania wskazują na to, że prawosławna parafia brańska przyjęła unię kościelną przed 1627 rokiem (Romaniuk 1993: 24). Według danych rejestru poborowego z 1674 roku w Kiersnowie było 20 rodzin unickich i 7 katolickich. ${ }^{5}$ Dwie dekady póżniej, zgodnie z informacjami zawartymi w rejestrze pogłównego z 1692 roku, zamieszkiwało tam 15 rodzin unickich i 12 katolickich. ${ }^{6}$ Liczby te ilustrują proces stopniowego przechodzenia unitów na obrządek rzymski. Wydaje się, że zaczął się on nasilać w II połowie XVII stulecia. Wobec braku odpowiednich danych, można tylko przypuszczać, o czym świadczą używane przez Kiersnowskich imiona, że w II połowie XVIII wieku wszyscy członkowie rodu byli już katolikami obrządku rzymskiego. W tym kontekście warto również zauważyć, że członkowie rodu bojarskiego, a poźniej szlacheckiego,

\footnotetext{
4 M 1708-1-84, k. 146.

5 ASK I 70, 421, 422.

6 KGB 52, 183 v., 200.
} 
Poletyłów, wywodzący się z sąsiedniej wsi Poletyły, zmienili wyznanie i obrządek nieco wcześniej (Zlotkowski 2017b: 180-181).

Na potrzeby tego artykułu wykorzystano materiał antroponimiczny wyekscerpowany z różnego rodzaju źródeł historycznych (zob. Skróty nazw wykorzystanych źródeł): ksiąg ziemskich i grodzkich brańskich, przechowywanych w Narodowym Archiwum Historycznym Białorusi w Mińsku, odpisów tychże ksiąg, znajdujących się w Archiwum Narodowym w Krakowie (tzw. Zespół Zygmunta Glogera), rejestrów popisów wojskowych szlachty WKL z 1528 i 1567 roku, spisu szlachty podlaskiej składającej przysięgę na wierność Koronie Polskiej w 1569 roku, dwóch rejestrów podatkowych powiatu bielskiego z 1674 i 1676 roku oraz spisu pogłównego parafii brańskiej (katolickiej i unickiej) z 1692 roku.

W zgromadzonym materiale źródłowym wyodrębnione zostały zapisy dotyczące poszczególnych osób. W miarę możliwości starano się dokonać ich właściwej identyfikacji. Nie zawsze było to możliwe i części inskrypcji nie udało się jednoznacznie zinterpretować. Pomocne okazały się dodatkowe informacje, wskazujące na relacje rodzinne, np. imię ojca, imię dziadka (rzadziej), przydomek gałęzi rodowej. Materiał źródłowy zawiera niekiedy opisy spraw majątkowych prowadzonych w grodzie brańskim, na podstawie których można zrekonstruować wzajemne powiązania rodzinne.

Nazwisko rodowe, którego pochodzenie zostało już wyjaśnione, pojawiło się w materiale archiwalnym dość wcześnie, bo już w 1528 roku, por. zapis: Iwan et Paulus filii Daszkonis Kierznowski.7 Analiza zgromadzonych poświadczeń źródłowych jest przesłanką do wnioskowania, że utrwaliło się w II połowie XVI wieku. Oprócz postaci podstawowej, która jest używana obecnie, funkcjonowało kilka wariantów fonetycznych nazwy, jak: Kirsnowski, Kierzsnowski, Kierznowski. Ten ostatni mógł utrwalić się pod wpływem wtórnego skojarzenia antroponimu ze staropolskim apelatywem kierz, oznaczającym krzak, krzew.

Zasób imion używanych przez członków omawianego rodu był w badanym okresie dosyć bogaty. Odnotowano ogółem 58 imion męskich, które identyfikowały około sto kilkadziesiąt osób. Jak już wspomniano, niemożliwe było ustalenie dokładnej liczby ich nosicieli. Oto podstawowe formy imion ułożone w kolejności alfabetycznej: Abraham, Aleksander, Andrzej, Bartłomiej, Bazyli, Benedykt, Bohdan, Charyton, Cyryl, Damian, Daniel, Dawid, Dymitr, Eliasz, Eustachy, Filemon, Filip, Filon, Franciszek, Gerazym, Grzegorz, Ignacy, Izydor, Jakub, Jan, Jerzy, Józef, Justyn, Kacper, Kalikst, Kalistrat, Kazimierz, Klemens, Konstanty, Krzysztof, Leon, Łukasz, Maciej, Marcin, Marcjan, Marek, Menas, Michat, Mikołaj, Pawet, Piotr, Prokop, Samuel, Sebastian, Seweryn, Sofroniusz, Stanisław, Stefan, Szymon, Teodor, Tomasz, Wawrzyniec, Wojciech. Należy zauważyć, że niektóre z nich 
zostały poświadczone nie w postaci oficjalnej (kanonicznej - cerkiewnej lub kościelnej) lecz potocznej, używanej na co dzień (m. in. w urzędzie). Są to następujące warianty imion: Oleszko (Aleksander), Wasil/Wasko (Bazyli), Bieniasz (Benedykt), Kuryło (Cyryl), Daniło (Daniel), Heliasz (Eliasz), Ostafij/Ostapko/Ostasz (Eustachy), Harasim (Gerazym), Hrehor/Hryc/Hrycz (Grzegorz), Ihnat (Ignacy), Sidor (Izydor), Iwan (Jan), Jesko/Jośko (Józef), Ustian (Justyn), Kalis (Kalistrat), Klim (Klemens), Kostiuk/Koszczuk (Konstanty), Lewon (Leon), Min (Menas), Misko (Michat), Paśko (Pawet), Stecko/Steczko (Stefan), Sofroniusz (Suprun), Siemion/Simon/Symon (Szymon), Chwedor/Chwiedko/Chwiedor (Teodor). Przedstawione warianty imion ukształtowane zostały w wyniku różnorakich modyfikacji fonetyczno-słowotwórczych, które dokonywały się w procesie ich adaptacji na grunt słowiański, albo w wyniku zmian, które zaszły już w lokalnym systemie antroponimicznym. Jeśli chodzi o imiona kobiece, udało się, z pozyskanych drogą ekscerpcji poświadczeń źródłowych, wyodrębnić 15 imion: Agapia, Aleksandra, Anastazja, Anna, Barbara, Dorota, Helena, Irena, Katarzyna, Krystyna, Maria, Marianna, Regina, Tatiana, Teodora. Mniejszą liczbę poświadczeń źródłowych imion żeńskich można tłumaczyć przyczynami kulturowymi (m. in. pozycją społeczną kobiet w tym czasie). W zgromadzonym materiale odnotowano zdecydowanie mniej wariantów fonetyczno-słowotwórczych imion kobiecych w porównaniu z męskimi. Poświadczone są następujące formy: Hasia/Ohapka (Agapia), Orysza (Irena), Maryna (Maria), Ragina/Raina (Regina), Tacianna (Tatiana), Chwiedora (Teodora). Wśród Kiersnowskich daje się na przestrzeni tych dwóch stuleci zaobserwować zjawisko stopniowego odchodzenia od imion (w postaciach podstawowych lub pochodnych) charakterystycznych dla wschodniosłowiańskiego kręgu kulturowego (prawosławni, unici) na rzecz imion popularnych wśród Słowian zachodnich (katolicy). Dotyczy to zarówno imiennictwa mężczyzn, jak i kobiet.

Imiona użyte do nominacji mężczyzn:

Abraham (Malec 1994: 175; Tichoniuk 2000: 64):

1. N[obi]lis Abrahami Kierznowski 1666 M 1708-1-158, k. 522; Nobilis Abrahami Kiersnowski 1663 M 1708-1-41, k. 471 v.

Aleksander /Oleszko/ (Malec 1994: 179-181, Tichoniuk 2000: 66):

1. Alexandro Kiersznowsky 1618 M 1708-1-31, k. 684 v.; No[bi]lis Alexandri Kierznowski 1617 M 1708-1-31, k. 233 v.; po niebosczyku Panu Alexandrze Kiersnowskiem 1663 M 1708-1-41, k. 565 v.; 2. Daszko/Daskowicz, syn Daniela w Poletyłach i Kiersnowie: Alexander oll Danielis Daszko de Kierznowo h[ae]r[e]s 1604 L 8121-7, k. 126 v.; Nobili Alexandro olim Danielis Kierznowski filio 1630 M 1708-1-206, k. 339 v.; Nobilis Alexandri Daskowicz Kiersnowski 1651 M 1708-1-141, k. 474.; 3. syn Jana: Nobil Alexandri olim Joann Kierznowski 1618 M 1708-1-31, k. 616; Nobilem 
Alexandrum olim Joannis Kierznowski 1618 M 1708-1-31, k. 615; 4. syn Jakuba /unita 1692/: Szl: Alexander Kierzsnowski 1676 BCz 1099, 828; P. Alexander olim Jakobi Kiersnowski 1692 KGB 52, 200; 4. /katolik 1692/: Szl: Alexander Kierznowski 1676 BCz 1099, 828; U Szlachetne[go] Alexandra Kiersnowskie[go] 1692 KGB 52, 183 v.; 5. syn Łukasza Bieniasowica /katolik 1674/: Alexander Kierznowski filius olim Lucae Kierznowski Bieniasowic 1667 M 1708-1-161, k. 107 v.; Slach Alexander Kierznowski 1674 ASK I 70, 421; G[e]n[er]osus Alexand[er] oli[m] Lucae Kierznowski 1695 M 1708-1-196, k.15 v.; 6. Ignatowicz Putyło: Олешко Игнатович 1528 RIB 33, 182 Andrzej (Malec 1994: 183-185, Tichoniuk 2000: 68-69):

1. Putiłowicz: Анъдрей Пучиловичъ 1567 RIB 33, 1099; Andreas, Laurentius olim Putilo 1569 AU 245; 2. Andreae Kierznowski 1602 L 812-1-7, k. 74; nobilis Hryc olim Andreae Kierznowski 1618 M 1708-1-31, k. 615 v.; 3. syn Hieronima: Joannes filius Hieronimi Kierznowski 1667 M 1708-1-161, k. 107 v.; 4. Sobiechowic: inter metas Andreae Sobiechowic 1668 M 1708-1-161, k. 632; 5. Cecelik, syn Teodora: No[bi]lis Andreas filius olim Theodori Kiersnowski Cecelik 1665 M 1708-1-158, k. 213; 6. Charytonowicz: Nlis Andreas Charytonowicz Kiersnowski 1597 ZZG 18, s. 289; 7. syn Tomasza: Nobilis Thomas Kierznowski [...] n[obi]libus Andreae Kierznowski filio suo 1643 M 1708-1-134, k 436

Bartłomiej (Malec 1994: 194-195, Tichoniuk 2000: 74-75):

1. Nobil[is] Bartolomei Kierznowski 1617 M 1708-1-31, k. 233 v.; 2. syn Bohdana Pawłowicza: Lewon, Bart[holo]maeus, Stephanus filii olim Bohdan Pawłowicz Kierznowski 1604 L 812-1-8, k. 1

Bazyli /Wasil,Wasko/ (Malec 1994: 196-197, Tichoniuk 2000: 75):

1. Szl[achetny] Bazyli Kierzsnowski 1676 BCz 1099, 828; 2. syn Filemona: Nobili Basilio Kierznowski filio Filimonis Kierznowski 1643 M 1708-1-133, k. 623 v.; 3. Ignatowicz (Putyło): Васко Игнатович 1528 RIB 33, 182

Bazyli /Wasil/ zob. Wawrzyniec:

1. Ostaszewicz: Василъ Осташевичъ 1567 RIB 33, 1099; Laurentius olim Ostasz 1569 AU 245

Benedykt /Bieniasz/ (Malec 1994: 197-198, Tichoniuk 2000: 75-76):

1. syn Stefana, burgrabia grodzki brański: Szlachetni [...] Bieniasz [...] Nieboszczyka Stefana Synowie 1586 ZZG 18, 98; Benedictum Kierznowski 1649 M 1708-1-37, k. 1542; ol[im] Nobilis Benedicti Kierznowski Burgrabii Castren[sis] Branscen[sis] 1672 M 1708-1-169, k. 144; 2. Putyło: Nlis Clemens Putiło Kierzsnowski [...] olim Benedicti 1630 M 1708-1-206, k. 121 v.; 3. syn Stefana Bohdanowica: N[obi]lem 
Benedictum filium Stephani Bochdanowic Kiersnowski 1650 M 1708-1-141, k. 290; Benedicto et Petro Kierznowskim 1643 M 1708-1-134, k 465

Bohdan (Tichoniuk 2000: 76-77):

1. Ihnat, Jessyo Bohdan którzy mieli dwoie Imienie Oyczyste nierozdzielne Kiersnowo w Bielskim, a Skoki w Brzeskiem Powiecie leżące 1501-1506 ZZG 18, 98; 2. Bohdani de Kiersznowo 1562 M 1708-1-4, k. 96; 3. Ostaszewicz: Богданъ Осташевичъ 1567 RIB 33, 1099; 4. Pawłoicz, syn Pawła: nobilis Bohdan olim Pauli de Kiersznowo 1562 M 1708-1-4, k. 103; Bohdan olim Pauli 1569 AU 245; śl. Bohdan Pawłoicz 1580 ŹDz 17, 124.

Charyton (Malec 1994: 203, Tichoniuk 2000: 78):

1. Ostaszewicz: Харытонъ Осташевичъ 1567 RIB 33, 1099; Charitom olim Ostasz 1569 AU 245

Cyryl /Kuryło/ (Malec 1994: 204-205, Tichoniuk 2000: 79):

1. Kuryło filius Kalisz de Kiersnowo 1571 ZZG 18, s. 582

Damian /Demian/ (Malec 1994: 205-206, Tichoniuk 2000: 79):

1. Nobilium Annae relictae ol[im] Demian Kierznowski 1599 M 1708-1-84, k. 146; 2. syn Mikołaja: Nico[la]us oll[im] Wasko Kierznowski cum Demiano filio suo de Kierznowo 1594 ZZG 18, s. 237; 3. syn Pawła Pacza: N[obi]lis Demian oll[im] Pauli Pacz Kiersnowki 1588 ZZG 17, s. 513; 4. Sidorzyk, syn Stefana Putyło: N[obi]lis Demianus Kierznowski filius ol[im] Stephani 1643 M 1708-1-134, k 232 v.; Nobilis Chwiedor Sidorzyk Kierznowski [...] Nobili Demian Kierznowski fr[atr]i suo 1643 M 1708-1-134, k 396; N[obi]lem Demianum olim Stephani Kierznowski 1649 M 1708-137, k. 1542

Daniel /Daniło/ (Malec 1994: 206-207, Tichoniuk 2000: 79):

1. Danielem Kiersnowski 1672 M 1708-1-49, k. 411 v.; 2. Bartoszyk/unita 1674/: Slach[etny] Daniel Bartoszyk 1674 ASK I 70, 422; 3. syn Iwana: Nobilis Ohapka filia nobilis Iwani de Kiersznowo [...] Nobili Daniło germano suo de ibid[em] 1562 M 1708-1-4, k. 434 v.; 4. syn Pawła: Nobil[is] Daniel olim Pauli Kierznowski 1623 M 1708-1-109, k. 193 v.; 5. Jeronimik / Jaromik, syn Stefana /unita 1674/: Nobilis Daniel filius n[obi]lis Stephani Jeronimik Kiersnowski 1651 M 1708-1-141, k. 634; Slach[etny] Daniel Jaromik 1674 ASK I 70, 422; Szl: Daniel Kierzsnowski 1676 BCz 1099; 6. syn Stefana Paszkowicza: Daniel et Joannes filii olim Stephani Paszkowicz 1667 M 1708-1-161, k. 107 v.; 7. syn Teodora /unita 1692/: Szl: Daniel Kierzsnowski 1676 BCz 1099, 828; P. Daniel olim Teodory Kiersno[wski] 1692 KGB 52, 200 
Dawid (Malec 1994: 207, Tichoniuk 2000: 80):

1. Filipik, syn Filipa Kaliszewicza /unita 1674/: Dawid filius olim Philipi Kierznowski Kaliszewic 1667 M 1708-1-161, k. 107 v.; Slach[etny] Dawid Philipik 1674 ASK I 70, 422; Nobilis Dauid olim Philippi Kiersnowski 1685 M 1708-1-182, k. 170; 2. syn Grzegorza /Hrehora, Hrycia/ Sokala: Dawid [...] oll[im] Hrycz Sokala Kierznowski 1602 L 812-1-7, k. 57 v; Nobilis Dauid filius olim Nobilis Hrehory Kiersnowski 1630 M 1708-1-206, k. 246.

Dymitr (Malec 1994: 210, Tichoniuk 2000: 81-82):

1. syn Andrzeja: N[o]b[ile]s Joannes, Philippus, Gregorius, Demetrius filii ol[im] N[obi]lis Andreae Kierznowski 1668 M 1708-1-161, k. 635 v.; 2. syn Wawrzyńca: Nobiles Demetrius et Gregorius olim Laurentii Kierznowski filii 1630 M 1708-1-206, k. $680 \mathrm{v}$.

Eliasz /Heliasz/ (Malec 1994: 211-212, Tichoniuk 2000: 83):

1. syn Antoniego: $N[o] b[i] l i s$ Chelias oli[m] Anton Kierznowski 1652 M 1708-1-38, k. $5 \mathrm{v}$.

Eustachy /Ostafij, Ostapko, Ostasz/ (Malec 1994: 190-191, Tichoniuk 2000: 87):

1. /unita 1692/: P. Ostafiy Kiersnowski 1692 KGB 52, 200; 2. syn Szymona/Siemiona: Ostapko ol[im] Siemion Kierznowski 1668 M 1708-1-161, k. 413 v.; Eustachium filium olim Simonis Kierznowski 1673 M 1708-1-49, k. 481; 3. syn Hieronima: ol[im] n[obi]les Eustachium quond[am] Hieronimi Kierznowski [1658] 1695 M 1708-1-196, k. 162 v.; 4. Markowicz /unita 1674/: Slach[Etny] Eustachy Markowicz 1674 ASK I 70, 422; 5. Jeskowicz: Осташъ Есковичъ 1528 RIB 33, 182

Filemon /Telimon/ (Malec 1994: 216, Tichoniuk 2000: 89):

1. ol[im] Philemonis Kiersnowski 1651 M 1708-1-141, k. 641 v.; 2. syn Iwana: Nobilis Thelimon filius olim Iwan Kierznowski 1643 M 1708-1-134, k 469

Filip (Malec 1994: 216, Tichoniuk 2000: 89):

1. N[obi]lem Anastasiam con[sor]tem Philippi Kiersnowski 1643 M 1708-1-134, k. 67; 2. Sobiesczuk [syn Andrzeja] /unita 1674/: N[o]b[ile]s Joannes, Philippus, Gregorius, Demetrius filii ol[im] N[obi]lis Andreae Kierznowski 1668 M 1708-1-161, k. 635 v.; Slach[etny] Philip Sobiesczuk 1674 ASK I 70, 422

Filon (Tichoniuk 2000: 90):

1. syn Mikołaja: Nobilis Filon filius nobilis Nicolai de Kiersnowo 1608 M 1708-1-98, k. 891 Franciszek (Malec 1994: 218-219, Tichoniuk 2000: 91):

1. N[obi]lis Franciscum olim Kierznowski in Poletyły haeredis 1672 M 1708-1-49, k. 366 
Gerazym /Harasim/ (Malec 1994: 224, Tichoniuk 2000: 92):

1. Klimi et Harasim Kiersnowskich 1608 M 1708-1-98, k. 891

Grzegorz /Hrehor / Hryc, Hrycz/ (Malec 1994: 228-229, Tichoniuk 2000: 93-94):

1. /katolik 1674/: Slach Grzegorz Kierznowski 1674 ASK I 70, 421; Szl: Grzegorz Kierzsnowski 1676 BCz 1099, 828; 2. /katolik 1692/: Sz. Grzegorz Kiersznowski 1692 KGB 52, 183 v.; 3. syn Pawła Sobechowicza /unita 1692/: P. Paweł Sobechowicz żona y syn Grzegorz 1692 KGB 52, 200; 4. syn Andrzeja: nobilis Hryc olim Andreae Kierznowski 1618 M 1708-1-31, k. 615 v.; Nobilis Joannes et Gregorius olim Andreae Kierznowscy 1663 M 1708-1-43, k.169; Hrehorius olim Andreae Kierznowski 1668 M 1708-1-161, k. 450; 5. syn Filemona: N[obi]lis Gregorii olim Philomon Kierznowski 1672 M 1708-1-49, k. 352 v.; 6. syn Hieronima: Joannes filius Hieronimi Kierznowski nomine suo et parentis ac Nobiliu[m] Simonis, Pauli, Andreae, Gregorii fratrum suorum germanorum 1667 M 1708-1-161, k. 107 v.; 7. Mienczukowicz: N[obi]les Gregorium Mienczukowicz Kiersnowski 1672 M 1708-1-49, k. 411 v.; 8. syn Pawła: n[obi]li Gregorio ol[im] Pauli Kierznowski 1695 M 1708-1-196, k. 216 v.; 9. syn Wawrzyńca: Gregorius olim Laurentii Kierznowski 1630 M 1708-1-206, k. 680 v.; Nobili Gregorio olim Laurentii Kierznowski 1643 M 1708-1-134, k 427 v.; 10. Śl. Hrycz Kiersnowski 1580 ŹDz 17, 124; 11. Nobilis Ohapka filia olim Hryc Kierznowski 1668 M 1708-1-161, k. 563; 12. Noskowicz: N[obi] lis Hryc Noskowicz de Kiersnowo 1588 ZZG 17, s. 510; 13. Oleszkowicz [syn Oleszka]: Nobilis Hrycz filius olim Oleszko de Kiersnowo Wozne 1562 M 1708-1-4, k. 222 v.; Hryc Oleszkowicz de Kiersnowo 1569 ZZG 18, s. 457

Grzegorz zob. Jerzy:

1. syn Stefana: N[obi]lis Georgius ol[im] Stephani Kiersnowski 1666 M 1708-1-158, k. 438; N[obi]lem Gregorium olim Stephani Kierznowski 1672 M 1708-1-49, k. 14 v. Ignacy /Ihnat/ (Malec 1994: 237-238, Tichoniuk 2000: 97):

1. Ihnat, Jessyo Bohdan którzy mieli dwoie Imienie Oyczyste nierozdzielne Kiersnowo w Bielskim, a Skoki w Brzeskiem Powiecie leżace 1501- 1506 ZZG 18, 98

Izydor /Sidor/ (Malec 1994: 239, Tichoniuk 2000: 97):

1. syn Wawrzyńca Korszen: N[obi]lis Sidor filius Laurenti Korszen de Kierznowo 1569 ZZG 18, s. 460

Jakub (Malec 1994: 239-243, Tichoniuk 2000: 98):

1. /unita 1692/: P. Jakub y Jan Kiersnowsci 1692 KGB 52, 200; 2. syn Piotra: n[obi]li Jacobo ol[im] Petri Kierznowski [1658] 1695 M 1708-1-196, k. 162 v.; 2. Ostapik/Ostapkowic, syn Eustachego/Ostafieja, wnuk Hieronima: Nobili Jacobo filio Ostaphiey Kierznowski 1643 M 1708-1-134, k 129; No[bi]lem Jacobum Ostapik Kiersnowski 1649 
M 1708-1-37, k. 784; N[obi]les Petrum et Jacobum Kierznowskich Ostapkowicow 1651 M 1708-1-141, k. 491 v.

Jan /Iwan/ (Malec 1994: 243-250, Tichoniuk 2000: 98-99):

1. /bojar ze Świryd/: Joannes Kierzsnowski de villa Swirydy [...] Haidones Sac[rae] R[e]g[i]ae M[aies]t[a]tis 1618 M 1708-1-31, k. 553; 2. Nobilem Joannem Kierznowski 1643 M 1708-1-134, k 129; n[obi]libus Joanne Kierznowski 1663 M 1708-1-41, k. 443 v.; nobilis Joannis Kierznowski 1668 M 1708-1-161, k. 563; 3. /unita 1692/: P. Jakub y Jan Kiersnowsci 1692 KGB 52, 200; 4. syn Andrzeja: Nobilis Joannes et Gregorius olim Andreae Kierznowscy 1663 M 1708-1-43, k.169; 5. syn Bieniasza / Benedykta /burgrabia grodzki brański/: Slachatny Wawrziniecz syn slachatnego Bieniasza Kierznowski swoim y braciey swey rodzoney Chwedora, Jana, Łukasza Kierznowskych 1618 M 1708-1-31, k. 485 v.; 6. Generosi at Nobiles Joannes Kierznowski Burgrabius Castren[sis] Branscens[is] filius olim Nobilis Benedicti Kierznowski 1667 M 1708-1161, k. 107 v.; 7. Chrystochowicz: Joannis Chrystochowicz 1652 M 1708-1-38, k. 5v.; 8. syn Filemona: Nobilis Joannes olim Philemonis Kiersnowski 1668 M 1708-1-161, k. 596 v.; 9. Filipik, syn Filipa Kaliszewicza /unita 1674/: Nobiles Joannem et Dauid filius olim Philippi Kierznowski 1663 M 1708-1-41, k. 471 v.; Slach[etny] Jan Philipik 1674 ASK I 70, 422; 10. Jaronimik, syn Hieronima /unita 1674/: Joannes filius Hieronimi Kierznowski 1667 M 1708-1-161, k. 107 v.; Slach Jan Jaronimik 1674 ASK I 70, 422; 11. Syn Iwana Skoczkowicza: Joannes, Nicolaus oll[im] Iwan Skoczkowicz [...] de Kiersnowo h[ae]r[e]des 1608 L 812-1-8, k. 77 v.; 12. syn Jakuba: n[obi]lis Joannes olim Jacobi Kierznowski [1658] 1695 M 1708-1-196, k. 162 v.; 13. syn Jerzego /katolik 1692/: Sz. Jerzy Kiersznowski Pani y Jan syn 1692 KGB 52, 183 v.; 14. syn Kalisiewicza: N[o]b[i]libus Dauid et Joanni filiis olim [...] Kalisewicz Kierznowski 1652 M 1708-1-38, k. 5V.; 15. syn Kaspra: Joanni, Christophero, Stanislao, Nicolao, Petro olim Gasparis Kierznowski 1599 M 1708-1-84, k. 270 v.; 16. syn Kuryła w Poletyłach: Chwiedor et Joannes filiis oll[im] Kuryło Kiersnowski in Poletyły h[ae]r[e]des 160o L 812-1-7, k. 11 v.; Nobil[is] Joannes olim Kuryło Kiersznowsky 1618 M 1708-1-31, k. 684; 17. syn Marcina: Albertum, Joannem et Dorotheam filios et filiam [...] olim Martini Kierznowski $1678 \mathrm{M}$ 1708-1-51, k. 25 v.; 18. Putyło/Putylik, syn Piotra /katolik 1674/: N[obi]les Joannem olim Petri Putylik Kierznowskim 1672 M 1708-1-49, k. 331; Slach[etny] Jan Kierznowski Putyło 1674 ASK I 70, 421; 19. Siemion: olim Nlis Joannis Semion Kierznowski 1668 M 1708-1-161, k. 632; 2o. syn Stefana Hieronimika: Nobiles [!] Joannes olim Stephani Hyeronimik Kierznowski 1668 M 1708-1-161, k. 450; Nobilis Joannes filius olim Stephani Kierznowski 1672 M 1708-1-49, k. 233; 21. syn Stefana Paszkowicza: Daniel et Joannes filii olim Stephani Paszkowicz 1667 M 1708-1-161, k. 107 v.; 22. syn Tomasza 
Tos: N[obi]lis Joannes filius Thomae Tos Kierznowski 1597 ZZG 18, s. 281; Nobili Joanni filio Nobilis Thomae Kiersnowski 1630 M 1708-1-206, k. 246; 23. Nobilibus Nicolao et Iwan de Kierznowo 1562 M 1708-1-4, k. 96; 24. Daszkowicz, syn Daszka: Иванъ Дашковичъ 1528 RIB 33, 182; Iwan et Paulus filii Daszkonis Kierznowski 1538 HerKap 170; 25. Miskowicz: Иванъ Мисковичъ 1567 RIB 33, 11оо; Iwan Miskowicz 1569 AU 245; 26. syn Pawła: Iwan przeszłego Pawła 1586 ZZG 18, 98; 27. syn Telimona: Nobilis Thelimon filius olim Iwan Kierznowski [...] nobili Iwano Kierznowski filio suo 1643 M 1708-1-134, k 469; 28. Tur: Iwan Thur 1569 AU 245; 29. Waskowicz Przynoszyk, syn Wawrzyńca: Иванъ Васковичъ Керсиновский 1567 RIB 33, 1099; Iwan olim Waszko 1569 AU 245; N[obi]lis Iwan oll[im] Laurentii Przynoszyk Kiersnowski 1593 ZZG 18, s. 225

Jerzy (Malec 1994: 251-253, Tichoniuk 2000: 100):

1. /katolik 1692/: Sz. Jerzy Kiersznowski 1692 KGB 52, 183 v.; 2. syn Stefana /katolik 1674/: Georgius olim Stephani Kierznowski 1667 M 1708-1-161, k. 107 v.; Slach[etny] Jerzy Kierznowski 1674 ASK I 70, 421

Jerzy zob. Grzegorz

Józef /Jesko, Jośko/ (Malec 1994: 300, Tichoniuk 2000: 101-102):

1. Ihnat, Jessyo, Bohdan którzy mieli dwoie Imienie Oyczyste nierozdzielne Kiersnowo w Bielskim, a Skoki w Brzeskiem Powiecie leżące 1501- 1506 ZZG 18, 98; 2. Gnatowicz Putyło/Putyłowski: Еско Кгнатовичъ Путило 1528 RIB 33, 182; N[obi]lis Joski Putylowski de Kierstnowo 1544 ZZG 20, s. 72; 3. Pienkowicz: Nobilium Josephi Mathai Pienkowicz [...] bonorum Kierznowo haeredum 1667 M 1708-1-161, k. 107 v.; 4. syn Stefana: Nobiles Georgium et Josephum filios olim n[obi]lis Stephani Kierznowski 1673 M 1708-1-49, k. 480 v.

Justyn /Ustian/ (Malec 1994: 257, Tichoniuk 2000: 102-103):

1. syn Grzegorza/Hryca Sokala: Ustyan filii oll[im] Hrycz Kiersnowski 16oo L 8121-7, k. 13; Nobilis Ustianus Kierznowski olim Gregorii 1630 M 1708-1-206, k. 487 v.; Ustianus ol[im] Hryc Kiersnowski 1643 M 1708-1-134, k. 67

Kacper /Kasper/ (Malec 1994: 258-259, Tichoniuk 2000: 104):

1. Касперъ Керсиновъски 1567 RIB 33, 1100; Casparum Kierznowski 1569 AU 245; circa sepulturum olim Gasparis Kierznowski in synagoga ruthenica Branscen[sis] 1599 M 1708-1-84, k. 146

Kalikst (Malec 1994: 257, Tichoniuk 2000: 103):

1. syn Wojciecha, poborcy ziemi bielskiej: N[obil]is Anastasia filia olim Stephani Kierznowski relicta primi ol[im] G[e]n[er]osi Alberi Kierznowski Exactor Terrae 
Bielscen[sis] ... nomine suo et N[obil]is Calixty Kierznowski priuigni sui 1668 M 17081-161, k. 413 v.

Kalistrat /Kalis/ (Tichoniuk 2000: 103):

1. Miskowicz, syn Mikołaja: Калисъ Мисковичъ 1567 RIB 33, 110о; Calisz olim Nicolai 1569 AU 245

Kazimierz (Tichoniuk 2000: 105):

1. syn Łukasza Bieniasowica /katolik 1674/: Alexander Kierznowski filius olim Lucae Kierznowski Bieniasowic nomine suo et Nobilis Casimiri Kierznowski sui germani 1667 M 1708-1-161, k. 107 v.; Slach[etny] Kazimierz Kierznowski 1674 ASK I 70, 421

Klemens /Klim/ (Malec 1994: 259-260, Tichoniuk, 2000: 105):

1. Klimi et Harasim Kiersnowskich 1608 M 1708-1-98, k. 891; 2. Putyło, syn Abrahama: Nobil[es] Siemion et Klym Putyłowie Kierznowscy 1618 M 1708-1-31, k. 615; N[obi]lem Clementem olim Abrahamis Kierznowski Putyło 1643 M 1708-1-134, k 150; 2. Markoicz, syn Marka: Nobilis Clementis olim Marci Kierznowski 1618 M 1708-131, k. 615; Nobilis Clemens Markoicz Kierznowski 1630 M 1708-1-206, k. 121; Nobilis Clemens alias Klym Kierzsnowski olim Marci 1630 M 1708-1-206, k. 229 v.; 3. syn Wawrzyńca Putyło: Clemens oll[im] Laurentii Putyło Kierznowski 1604 L 812-1-8, k. 1 v.; Nobilis Klim olim Nobilis Laurentii Kierznowski 1643 M 1708-1-134, k 129

Konstanty /Kostiuk, Koszczuk/ (Malec 1994: 264, Tichoniuk 2000: 106-107):

1. olim N[o]b[i]lis Constantini Kierznowski 1665 M 1708-1-158, k. 275 v.; 2. syn Sebastiana: N[obi]lis Constantinus ol[im] Sebestiani Kiersnowski 1643 M 1708-1-134, k. 67 v.; 3. syn Oleszka: Nobilis Hrycz filius olim Oleszko de Kiersnowo Wozne [...] Kosczuk germanum suum de ibid[em] 1562 M 1708-1-4, k. 222 v.; 4. Waskowicz: Костюкъ Васковичъ Керсиновский 1567 RIB 33, 1099; Coscziuk olim Waszko 1569 AU 245 Krzysztof (Malec 1994: 266-267, Tichoniuk 2000: 108):

1. Nob[ilib]us Chr[ist]ophero Kierznowski et Simone Poletyłowski 1601 M 1708-1-91, k. 453; 2. syn Kaspra: Joanni, Christophero, Stanislao, Nicolao, Petro olim Gasparis Kierznowski 1599 M 1708-1-84, k. 270 v.; 3. syn Kuryła: Chr[ist]oph[or]um olim Kuriło Kiersnowski de Poleteły h[ae]r[e]s 1608 M 1708-1-98, k. 891 v.

Leon /Lewon/ (Malec 1994: 270, Tichoniuk 2000: 109-110):

1. syn Bohdana Pawłowicza: Lewon, Bart[holo]maeus, Stephanus filii olim Bohdan Pawłowicz Kierznowski 1604 L 812-1-8, k. 1

Łukasz (Malec 1994: 273; Tichoniuk 2000: 111-112):

1. Śl. Łukasz z Siemionem 1580 ŹDz 17, 124; 2. Nobilem Lucam Kiersnowski 1599 M 1708-1-84, k. 13; 3. /unita 1692/: P. Łukasz Kiersnowski 1692 KGB 52, 200; 4. Nobilis Fiedor Skokowski de Ducatu Lithvaniae Districtu Brzestensi filus olim Siemion 
Skokowski de Skoki, suo et nomie NN. Petri Lucae fratrum Germanorum de Bonis Kierznowo hoc in Districtu Bielscensi 1586 ZZG 18, 99; 5. Bieniasowic, syn Bieniasza/Benedykta: nobili Lucae olim Benedicti Kierznowski 1630 M 1708-1-206, k. 487 v.; olim Lucae Kierznowski Bieniasowic 1667 M 1708-1-161, k. 107 v.; 6. syn Stefana: Szlachetni [...] Łukasz Nieboszczyka Stefana Synowie 1586 ZZG 18, 98; Nobilis Lucae olim Stephani Kierznowski 1599 M 1708-1-84, k. 270 v.

Maciej (Malec 1994: 274-277, Tichoniuk 2000: 112):

1. Pienkowicz: Nobilium Josephi Mathai Pienkowicz [...] bonorum Kierznowo haeredum 1667 M 1708-1-161, k. 107 v.

Marcin zob. Marcjan (Malec 1994: 279-280, Tichoniuk 2000: 114):

1. Pan Jan Kierznowski swym y stryiecznego swego Pana Marcina Kierznowskiego imieniem 1663 M 1708-1-41, k. 565 v.; 2. syn Aleksandra Daskowicza w Kiersnowie, Hryniewiczach i Poletyłach /burgrabia grodzki brański/: Nobilis Martinus Kiersnowski filius N[obi]lis Alexandri Kierznowski de Hryniewice et Kierznowo h[ae] r[e]s 1643 M 1708-1-134, k 121 v.; N[obi]lis Martinus Kiersnowski Burgrabius Castren[sis] Branscen[sis] 1665 M 1708-1-159, k. 231; Nobiles Martinum oli[m] Alexandri Daszkoicz Kierznowski 1655 M 1708-1-39, k. 274; Nobilis Martinus filius olim Nobilis Alexandri Kierznowski in Poletyły haeres 1673 M 1708-1-169, k. 502 v.; 3. syn Daniela: Nobilis Martini ol[im] Danielis Kierznowski 1643 M 1708-1-133, k. 623 v.; 4. Ustianik /unita 1674/: Slach[etny] Marcin Ustianik 1674 ASK I 70, 422; Szl[achetny] Marcin Kierzsnowski 1676 BCz 1099, 829

Marcjan zob. Marcin (Malec 1994: 280, Tichoniuk 2000: 114):

1. Androsik / Andruszczyk, syn Chwedora / Teodora /unita 1674/: $N[o] b[i] l i s$ Martiano olim Chwiedori Kierznowski 1665 M 1708-1-158, k. 275 v.; N[obi]lem Martinum filium olim Chwiedoris Andruscyk Kierznowski 1667 M 1708-1-45, k. 75; Slach[etny] Marcin Androsik 1674 ASK I 70, 422; 828

Marek (Malec 1994: 280-281, Tichoniuk 2000: 114):

1. Daskowicz, syn Jana / Iwana: Марекъ Дасковичъ 1567 RIB 33, 1099; Marcus olim Joannis 1569 AU 245; Marci filii oll[im] Iwan Daszkowicz Kierznowski 1602 L 812-1-7, k. 72

Menas /Min/ (Tichoniuk 2000: 116):

1. syn Iwana /wójt w Hołodach/: Min oll[im] Iwan Kiersnowski advocatus in villa Hołody 1587 ZZG 17, s. 475

Michał /Misko/ (Malec 1994: 284-285, Tichoniuk 2000: 117):

1. Jeskowicz: Миско Есковичъ 1528 RIB 33, 182 
Mikołaj (Malec 1994: 285-292, Tichoniuk 2000: 117):

1. N[obi]lem Nicolaum Kierznowski 1630 M 1708-1-206, k. 8; 2. Nobilibus Nicolao et Iwan de Kierznowo 1562 M 1708-1-4, k. 96; 3. /katolik 1674/: Slach[etni] Mikołay y Stanisław Kierznowscy 1674 ASK I 70, 421; 4. /katolik 1692/: Sz. Mikołay Kiersznowski 1692 KGB 52, 183 v.; 5. syn Iwana Skoczkowicza: Joannes, Nicolaus oll[im] Iwan Skoczkowicz [...] de Kiersnowo h[ae]r[e]des 1608 L 812-1-8, k. 77 v.; 6. syn Kaspra: Joanni, Christophero, Stanislao, Nicolao, Petro olim Gasparis Kierznowski 1599 M 1708-1-84, k. 270 v.; 7. Klimunciak, syn Klemensa: Nicolaum olim Clementis Kierznowski 1672 M 1708-1-49, k. 331; Szl[achetny] Mikołay Klimunciak 1676 BCz 1099, 829; 8. syn Marcina: N[obi]lis Nicolaus filius Martini Kierznowski 1695 M 1708-1-196, k. 216 v.; 9. Waskowicz, syn Waska/Wawrzyńca: Миколай Васковичъ Керсиновский 1567 RIB 33, 1099; Nicolaus olim Laurentii 1569 AU 245; Nico[la]us oll[im] Wasko Kierznowski 1594 ZZG 18, s. 237

Paweł /Paśko/ (Malec 1994: 303-305, Tichoniuk 2000: 122-123):

1. Charytonowicz: Supron filius Pauli Charytonowicz Kierznowski 1602 L 812-1-7, k. 64 v.; 2. Daszkowicz, syn Daszka: Iwan et Paulus filii Daszkonis Kierznowski 1538 HerKap 170; Павелъ Дашковичъ Керсиновский 1567 RIB 33, 1100; Paulus olim Daskowicz 1569 AU 245; 3. syn Stanisława: Paśko Filus Stanislai 1537 HerKap 170; 4. Szyło: N[obi]lem Paulum Szyło Kiersnowski 1668 M 1708-1-161, k. 6oo; 5. syn Hieronima: Nobilis Paulus filius n[obi]lis Hieronimi Kierznowski 1673 M 1708-1-49, k. 480 v.; 6. Kostiuszyk/Konstanczyk, syn Konstantego /unita 1674/: Slach[etny] Paweł Kostiuszyk 1674 ASK I 70, 422; Szl[achetny] Pawet Konstanczyk 1676 BCz 1099, 828; n[obi]li Paulo ol[im] Constantini Kierznowski 1676 M 1708-1-172, k. 50; 7. Sobechowicz /unita 1692/: P. Pawet Sobechowicz 1692 KGB 52, 200

Piotr (Malec 1994: 306-310, Tichoniuk 2000: 123-124):

1. N[obi]libus Petro et Luca Kierznowskiemi 1643 M 1708-1-134, k. 52 v.; N[obi]lis Petrus Kiersnowski 1665 M 1708-1-159, k. 147 v.; 2. syn Aleksandra: n[obi]lis Petrus filius n[obi]lis Alexandri Kierznowski 1643 M 1708-1-134, k 297; 3. Ostapkowic/ Ostafieik/Ostapczyk, syn Eustachego /unita 1674/: N[obi]les Petrum et Jacobum Kierznowskich Ostapkowicow 1651 M 1708-1-141, k. 491 v.; N[obi]lis Petrus olim Eustachii Kiersnowski 1665 M 1708-1-158, k. 161; N[obi]lis Petri Ostapheik Kiersnowski 1668 M 1708-1-161, k. 632; Slach[etny] Piotr Ostapczyk 1674 ASK I 70, 422; 4. syn Kaspra: Joanni, Christophero, Stanislao, Nicolao, Petro olim Gasparis Kierznowski 1599 M 1708-1-84, k. 270 v.; 5. Bohdanowicz, syn Stefana Bohdana/Bohdanowic(z)a/Bohdanika /unita 1674/: N[obi]lis Stephanum olim Bohdan Kierznowski [...] Benedicto et Petro Kierznowskim filiis suis 1643 M 1708-1-134, k 465; Nobili Petro 
filio olim no[bi]lis Stephani Bochdanik Kiersnowski 1665 M 1708-1-158, k. 213; N[obi] lis Petrus ol[im] Stephani Bohdan Kierznowski 1666 M 1708-1-158, k. 522; Slach[etny] Piotr Bohdanowicz 1674 ASK I 70, 422; 6. syn Siemiona: Nobilis Fiedor Skokowski de Ducatu Lithvaniae Districtu Brzestensi filus olim Siemion Skokowski de Skoki, suo et nomie NN. Petri, Lucae fratrum Germanorum de Bonis Kierznowo hoc in Districtu Bielscensi 1586 ZZG 18, 99; 7. Putyło, syn Siemiona/Szymona: Petri Putyło Kierzsnowski 1630 M 1708-1-206, k. 121 v.; Petrus olim Simonis Putyło Kierznowski 1663 M 1708-1-43, k. 212

Prokop (Malec 1994: 313, Tichoniuk 2000: 125):

1. syn Eliasza: n[obi]lis Procopius olim Eliae Kierznowski 1695 M 1708-1-196, k. 74 v.

Samuel (Malec 1994: 321, Tichoniuk 2000: 129):

1. /namiestnik majętności Knorydy/: Urodzony Pan Samuel Kierznowski Namiesnik Maiętnosci Knoryd 1663 M 1708-1-41, k. 247; 2. syn Hieronima: Nobilis Samuel olim Hyeronimi Kierznowski 1690 M 1708-1-57, k. 855 v.

Sebastian (Malec 1994: 321-322, Tichoniuk 2000: 129):

1. syn Daniela: Sebestianus et Alexander olim Daniel Kierznowski 1618 M 1708-1-31, k. $615 \mathrm{v}$.

Seweryn (Malec 1994: 322-323, Tichoniuk 2000: 130):

1. syn Dawida: N[obi]l[i]s Seuerinus filius N[obi]lis Dauidis Kierznowski 1643 M 1708-1-134, k 342 v.; 2. syn Jana, wnuk Stefana: n[obi]lis Seuerinus ol[im] Joannis Kierznowski 1695 M 1708-1-196, k. 144

Sofroniusz /Suprun/ (Malec 1994: 323, Tichoniuk 2000: 130-131):

1. syn Pawła Charytonowicza: Supron filius Pauli Charytonowicz Kierznowski 1602 L 812-1-7, k. 64 V.

Stanisław (Malec 1994: 323, Tichoniuk 2000: 131):

1. Станиславъ Керсиновский 1567 RIB 33, 1099; 2. Nobilis Christophero et Stanislao Kierznowskie 1599 M 1708-1-84, k. 146; 3. /unita 1674/: Slach[etni] Mikołay y Stanisław Kierznowscy 1674 ASK I 70, 421; 4. /pisarz ziemski starodubski/: G[e]n[ero] oso Stanislao Kierznowski Notario T[e]rr[estr]i Starodubiens[i] 1643 M 1708-1-134, k 295 v.; 5. syn Kaspra: Joanni, Christophero, Stanislao, Nicolao Petro olim Gasparis Kierznowski 1599 M 1708-1-84, k. 270 v.; 6. syn Pawła: Nobilis Stanislaus olim Pauli Kierznowski 1685 M 1708-1-182, k. 303; 7. syn Seweryna: Nobilis Stanislaus olim Seuerini Kierznowski 1673 M 1708-1-49, k. 479 v.; Szl[achetny] Stanisław Kierzsnowski $1676 \mathrm{BCz} 1099,828$ 
Stefan /Stecko, Steczko/ (Malec 1994:325-326, Tichoniuk 2000: 131-132):

1. Waskowicz, syn Waśka: Nobilem Steczko olim Vasko de Kiersznowo 1562 M 17081-4, k. 141 v.; Стецъко Васковичъ Керсиновский 1567 RIB 33, 1099; Steczko oll[im] Wasko de Kiersnowo 1567 ZZG 17, s. 140; Steczko olim Laurentii 1569 AU 245; 2. syn Bohdana Pawłowicza: Stephanus filii olim Bohdan Pawłowicz Kierznowski 1604 L 812-1-8, k. 1; N[obi]lis Stephanum olim Bohdan Kierznowski 1643 M 1708-1-134, k 465; 3. /unita 1692/: Jm. P. Stefan Kiersnowski 1692 KGB 52, 200

Szymon /Siemion, Simon, Symon/ (Malec 1994: 326-327, Tichoniuk 2000: 134):

1. /unita 1692/: P. Szymon Kiersnowski 1692 KGB 52, 200; 2. Śl. Łukasz z Siemionem 1580 ŹDz 17, 124; 3. Putyło: Nobil[es] Siemion et Klym Putyłowie Kierznowscy 1618 M 1708-1-31, k. 615; 4. syn Hieronima: N[obi]lis Simon filius n[obi]lis Hieronimi Kierznowski 1672 M 1708-1-49, k. 388; 5. Klimowic Abrahamowic: ol[im] [...] Siemion Klimowic Abrahamowic Kierznowski 1668 M 1708-1-161, k. 413 v.; 6. Markowic: Simonis Markowic 1663 M 1708-1-43, k.169; 7. syn Benedykta: Siemion ol[im] Benedicti Kierznowski 1668 M 1708-1-161, k. 415; 8. Jarosik, syn Hieronima /unita 1674/: Joannes filius Hieronimi Kierznowski nomine suo et [...] Nobiliu[m] Simonis [...] fratrum suorum germanorum 1667 M 1708-1-161, k. 107 v.; Slach[etny] Symon Jarosik 1674 ASK I 70, 422; 9. syn Jana, wnuk Stefana: n[obi]lis Seuerinus ol[im] Joannis Kierznowski [...] et n[obi]l[i]um Simonis ac Theodori Kierznowskich fratrum suor[um] germanom[um] 1695 M 1708-1-196, k. 144; 10. syn Konstantego: Nobilis Simon ol[im] Constantini Kierznowski 1651 M 1708-1-141, k. 602 v.

Teodor /Chwedor, Chwiedko, Chwiedor/ (Malec 1994: 330-331, Tichoniuk 2000: 136):

1. N[obi]lem Chwiedorem Kierznowski 1630 M 1708-1-206, k. 113 v.; nobilium Joannis et Chwiedori Kierznowskich 1672 M 1708-1-49, k. 331; 2. Bartosowic, wnuk Bohdana: Nobilis Chwiedor Bartosowic 1667 M 1708-1-161, k. 107 v.; 3. syn Bieniasza: Chwedora, Jana, Łukasza Kierznowskych 1618 M 1708-1-31, k. 485 v.; 4. syn Hrycza Sokala: Dawid, Chwiedor et Ustian filii oll[im] Hrycz Sokala Kierznowski 1602 L 8121-7, k. 57 v.; 5. syn Kuryła w Poletyłach: Chwiedor et Joannes filiis oll[im] Kuryto Kiersnowski in Poletyły h[ae]r[e]des 16oo L 812-1-7, k. 11 v.; 6. syn Michała: Chwietko Filus Michaelis 1537 HerKap 170; 7. Sidorzyk, syn Stefana Putyło: Nobilis Chwiedor Sidorzyk Kierznowski 1643 M 1708-1-134, k 396; No[bi]lem Chwiedor ol Stephani Putyło Kiersnowski 1649 M 1708-1-37, k. 1677; 8. syn Andrzeja: N[obi]li Theodoro ol[im] Andreae Kiersnowski 1643 M 1708-1-134, k. 67 v.; 9. syn Jana, wnuk Stefana: n[obi]lis Seuerinus ol[im] Joannis Kierznowski [...] et n[nobi]lum Simonis ac Theodori Kierznowskich fratrum suor[um] germanom[um] 1695 M 1708-1-196, k. 144; 10. Sawczuk /unita 1674/: Slach[etny] Theodor Sawczuk 1674 ASK I 70, 422 
Tomasz (Malec 1994: 332-333, Tichoniuk 2000: 138-139):

1. Nobilis Thomas Kierznowski 1643 M 1708-1-134, k 436; 2. Tosz: N[obi]lis Thomasz Tosz Kierznowski 1593 ZZG 18, s. 230

Wawrzyniec (Malec 1994: 339-340, Tichoniuk 2000: 109):

1. Nobilis Laurentius Kierznowski 1562 M 1708-1-4, k. 105; 2. /katolik 1692/: Sz[lachety] Wawrzyniec Kiersznowski 1692 KGB 52, 183 v.; 3. Putitowicz: Вавърынецъ Пучиловъ сынъ 1567 RIB 33, 1099; Andreas, Laurentius olim Putilo 1569 AU 245; 4. syn Bieniasza: 1618 M 1708-1-31, k. 485 v.

Wawrzyniec zob. Bazyli

Wojciech (Malec 1994: 345, Tichoniuk 2000: 142-143):

1. /unita 1692/: P. Dawidowa Kiersnowska, syn Woyciech z żonq 1692 KGB 52, $200 ; 2$. /komornik graniczny i poborca ziemi bielskiej/: G[e]n[er]osi Alberti Kierznowski Camerarii Granicialis et Exactoris Terrae Bielscens[is] 1655 M 1708-1-39, k. 274; Urodzonego Woyciecha Kiersnowskiego Poborcy Ziemie Bielskiey 1665 M 1708-1-159, k. 382; 3. Daszkiewicz, syn Aleksandra Daskowicza: N[obi]lium Alberti ol[im] Alexandri Basikowicz [!] Kierznowski 1649 M 1708-1-37, k. 1358; Młyn Kierznowo nazwany Daszkowsczyzna po Panu Woyciechu Kierznowskim Daszkiewiczu 1663 M 1708-1-43, k. 484; 4. Kleskiewicz: Alberti Kierznowski Kleskiewicz 1672 M 1708-1-49, k. 313 v.; 5. syn Marcina w Poletyłach: Albertum, Joannem et Dorotheam filios et filiam [...] olim Martini Kierznowski 1678 M 1708-1-51, k. 25 v.; G[e]n[er]osus Albertus ol[im] G[enerosi] Martini Kierznowski in Poletyty h[ae]r[e]s 1695 M 1708-1-196, k. 236 v. Imiona użyte do nominacji kobiet:

Agapia /Hasia, Ohapka/ (Malec 1994: 350, Tichoniuk 2000: 64-65):

1. córka Iwana Kiersnowskiego: Nobilis Ohapka filia nobilis Iwani de Kiersznowo 1562 M 1708-1-4, k. 434 v.; 2. córka Hryca Kiersnowskiego, żona Jana Kiersnowskiego: Nobilis Ohapka filia olim Hryc Kierznowski consors nobilis Joannis Kierznowski 1668 M 1708-1-161, k. 563; 3. żona Andrzeja Kiersnowskiego, córka Mikołaja Kiersnowskiego: Hasia filia oll[im] Nico]la]i Kierznowski C[o]ns[ors] Andreae Kierznowski 1602 L 812-1-7, k. 74

Aleksandra (Malec 1994: 351, Tichoniuk 2000: 66):

1. Pobikrowska, żona Aleksandra Kiersnowskiego: Nobil[em] Alexandrum olim Danielis Kiersnowski Petronellam Pobikrowska Consortem eiusd[em] Alexandri 1625 M 1708-1-35, k. 67 v.

Anastazja (Malec 1994: 352, Tichoniuk 2000: 68):

1. żona Filipa Kiersnowskiego: N[obi]lem Anastasiam con[sor]tem Philippi Kiersnowski 1643 M 1708-1-134, k. 67; 2. Kiersnowska, żona Bartłomieja Piotrowskiego: 
n[obi]lis Anastasia Kierznowska relicta consors ol[im] n[obi]lis Bartholomaei Piotrowski 1695 M 1708-1-196, k. 219; 3. córka Stefana Kiersnowskiego, żona Wojciecha Kiersnowskiego poborcy ziemi bielskiej: Urodzona Anastasia Kiersnowska małzonka pozostała Urodzonego Woyciecha Kiersnowskiego Poborcy Ziemie Bielskiey 1665 M 1708-1-159, k. 382; 4. córka Marka Daszkowicza Kiersnowskiego, żona Lecza Kotowicza: Anastazia filia Marci filii oll[im] Iwan Daszkowicz Kierznowski de Kierznowo h[ae]r[e]dis C[o]ns[ors] Rell[icta] oll[im] Lecz Kotowicz 1602 L 812-1-7, k. 72

Anna (Malec 1994: 352-353, Tichoniuk 2000: 69-70):

1. żona Demiana Kiersnowskiego: Nobilium Annae relictae ol[im] Demian Kierznowski 1599 M 1708-1-84, k. 146; 2. córka Konstantego Kiersnowskiego, żona Wawrzyńca Kiersnowskiego: Nobilis Anna filia olim Constantini Kierznowski relicta consors olim Laurentii Kierznowski 1630 M 1708-1-206, k. 680 v.; 3. córka Wawrzyńca Kiersnowskiego: Annae filiae olim Laurentii Kierznowski virginis 1599 M 1708-1-84, k. 146; 4. żona Pawła Kiersnowskiego: Nobilis Anna consors Nobilis Pauli Kiersnowsky 1599 M 1708-1-84, k. 370 v.; 5. Bańkowska, żona Konstantego Kiersnowskiego: $N[o] b[i] l i s$ Anna Bankowska relicta olim N[o]b[i]lis Constantini Kierznowski 1665 M 1708-1-158, k. 275 v.; 6. córka (Jana) Siemiona Kiersnowskiego, żona Piotra Ostafieika Kiersnowskiego: N[obi]lis Anna filia olim N[obi]lis Joannis Semion Kierznowski consors ad praes[ens] Nlis Petri Ostapheik Kiersnowski 1668 M 1708-1-161, k. 632;

Barbara (Malec 1994: 355, Tichoniuk 2000: 74):

1. żona Józefa Hryniewickiego: nobilis Josephus olim Moysei Hryniewicki nomine suo et nobilis Barbarae Kierznowska coniuge suae 1668 M 1708-1-161, k. 448 v.

Dorota (Malec 1994: 357-358, Tichoniuk 2000: 81):

1. córka Iwana Kiersnowskiego: olim [...] Dorotheae filios quondam Iwan Kierznowski 1668 M 1708-1-161, k. 635 v.; 2. córka Marcina Kiersnowskiego: Dorotheam filios [...] filiam [...] olim Martini Kierznowski 1678 M 1708-1-51, k. 25 v.; 3. córka Wawrzyńca Kiersnowskiego, żona Michała Paczewicza: Nobilium [...] Dorotheae consort[...] Michaelis Paczewicz [...] filiae olim Laurentii Kierznowski 1599 M 17081-84, k. 146

Helena (Malec 1994: 365-366, Tichoniuk 2000: 94-95):

1. Poletyło, żona Marcina Kiersnowskiego: N[obi]lis Haelenam olim Alexandri Poletyło con[sor]tem n[obi]lis Martini Kierznowski 1678 M 1708-1-51, k. 508; 2. córka Demiana Putyło Kiersnowskiego, żona Szymona Sakowskiego: Nobilis Helena olim Demiani Putyło Kierznowski consors vero Nobilis Simonis Sakowski 1674 M 1708-1-170, k. 52; 3. Makowska, żona Wojciecha Kiersnowskiego w Poletyłach: 
G[e]n[er]osus Albertus ol[im] G[enerosi] Martini Kierznowski in Poletyty h[ae]r[e]s atq[ue] Helena Makowska coniuges 1695 M 1708-1-196, k. 236 v.

Irena /Orysza/ (Malec 1994: 366, Tichoniuk 2000: 97):

1. córka Andrzeja Kiersnowskiego, żona Hrycza Mierynowicza (Mierynowiecz): Orysza filia oll[im] Andreae de Kierznowo Rell[ict]a C[o]ns[ors] oll[im] Hrycz Mierynowiecz 1604 L 812-1-7, k. 129 v.

Katarzyna (Malec 1994:370-371, Tichoniuk 2000: 104):

1. żona Andrzeja Kiersnowskiego: Nobilis Cateryna relicta consors olim Nobilis Andreae Kierznowsky 1618 M 1708-1-31, k. 615 v.; 2. Popławska, żona Jerzego Kiersnowskiego: N[obi]lis Georgius ol[im] Stephani Kiersnowski de Kiersnowo h[ae] r[e]s [...] N[obi]li Catharinae filiae ol[im] N[obi]lis Joannis Kazimierouicz Popławski consorti suae 1666 M 1708-1-158, k. 438; 3. żona Benedykta Kiersowskiego: Nobilis Catherina uxor Nobilis Benedicti Kiersnowski 1599 M 1708-1-84, k. 13

Krystyna (Malec 1994: 372, Tichoniuk 2000: 108):

1. Sakowska, żona Samuela Kiersnowskiego: Nobilis Samuel olim Hyeronimi Kierznowski de Kierznowo haeres [...] Nobili Cristinae Sakowska consorti suae 1690 M 1708-1-57, k. 855 v.

Maria /Maryna/ (zob. Marianna) (Malec 1994:376-377, Tichoniuk 2000: 114):

1. [unitka 1692]: P. Łukasz Kiersnowski y siostra Maryna 1692 KGB 52, 200; 2. Szl[achetna] Maryna Poletyłowa z corka 1676 BCz 1099, 828; 3. córka Iwana Kiersnowskiego: Honesta Marina filia olim Nobilis Iwan Kierznowski consors Honesti Szafier de Malesze 1643 M 1708-1-134, k 415; 4. Chomanowicowna, żona Benedykta Kiersnowskiego: n[obi]lis Mariae Chomanowicowna relicta con[sor] tis ol[im] n[obi]lis Benedicti Kierznowski 1663 M 1708-1-41, k. 443 v.; 5. córka lub żona Chwedora Kiersnowskiego: N[obi]lem Marinam olim Chwiedor Kierznowski 1662 M 1708-1-153, k. 439;

Marianna (zob. Maria) (Malec 1994: 377, Tichoniuk 2000: 114-115):

1. Hajewnikowna Hryniewicka, żona Marcina Kiersnowskiego w Poletyłach: n[obi]lem Martinum Kierznowski filium Alexandri et Mariannam Haiewnikowna Hryniewicka coniuges 1643 M 1708-1-134, k. 52 v.; n[obi]lis Marinam Hryniewicka relictam consors olim n[obi]lis Martini Kiersnowski in bonorum Poletyły 1678 M 17081-51, k. 25 V.

Regina /Raina, Ragina/ (Malec 1994: 382, Tichoniuk 2000: 126):

1. Daszkowna, żona Jana Kiersnowskiego: Joannes Kiersnowski cum Ragina Daszkowna con[sor]te sua 1600 L 812-1-7, k. 11 v.; Nobil[is] Joannes olim Kuryło Kiersznowsky et Raina Consors eiusd[em] Joannis 1618 M 1708-1-31, k. 684 
Tatiana /Tacianna/ (Malec 1994: 384, Tichoniuk 2000: 135):

1. żona Daniela Kiersnowskiego: Alexander oll[im] Danielis Daszko de Kierznowo h[ae]r[es]s ex Tacianna ad praesens Con[sor]te Matthaei Radziszewski p[ro]creatus filius 1604 L 812-1-7, k. 126 v.

Teodora /Chwiedora/ (Malec 1994: 384-385, Tichoniuk 2000: 136-137):

1. córka Chwiedora Kiersnowskiego, żona Abrahama Kiersnowskiego: Nobilem Chwiedoram filiam olim Chwiedor Kiersnowski consortem Nobilis Abrahami Kiersnowski 1663 M 1708-1-41, k. 471 v.

Oprócz nazwiska i imion członkowie rodu Kiersnowskich posługiwali się dodatkowymi elementami identyfikacji antroponimicznej, róźnie nazywanymi przez badaczy. Antroponomaści określają je mianem nazwisk historycznych, protonazwisk, przezwisk, przydomków lub określeń dodatkowych. Jednostki te, w zależności od ich budowy słowotwórczej, mogły być strukturami prostymi, albo, poszerzone o dodatkowe wykładniki formalne, miały charakter derywatów antroponimicznych o charakterze przezwiskowym lub przydomkowym bądź struktur patronimicznych (odimiennych). W zgromadzonym materiale źródłowym przeważały zdecydowanie formacje derywowane. Należy zwrócić uwagę na różną popularność formantów tworzących te struktury w poszczególnych stuleciach. I tak, antroponimy na -icz, -(ow)icz, -(ew)icz były w użyciu zarówno w XVI, jak i XVII wieku, a więc praktycznie w ciągu całego badanego okresu. Udało się wyekscerpować 26 jednostek onimicznych tego typu. Zdecydowaną przewagę mają tu antroponimy odimienne, odnotowane w liczbie 22 :

Abrahamowic: ol[im] N[obi]l[e]m Siemion Klimowic Abrahamowic Kierznowski 1668 M 17081-161, k. $413 \mathrm{~V}$.

Bartosowic: Nobilis Chwiedor Bartosowic 1667 M 1708-1-161, k. 107 V.

Bieniasowic: Alexander Kierznowski filius olim Lucae Kierznowski Bieniasowic 1667 M 17081-161, k. $107 \mathrm{~V}$.

Bohdanowic / Bohdanowicz: N[obi]lem Benedictum filium Stephani Bochdanowic Kiersnowski 1650 M 1708-1-141, k. 290; Petrus Kierznowski filius olim Stephani Bohdanowicz Kierznowski 1667 M 1708-1-161, k. 107 v.; Slach[etny] Piotr Bohdanowicz 1674 ASK I 70,422

Charytonowicz: N[obi]lis Andreas Charytonowicz Kiersnowski 1597 ZZG 18, s. 289; Supron filius Pauli Charytonowicz Kierznowski 1602 L 812-1-7, k. 64 v.

Chrystochowicz: Joannis Chrystochowicz 1652 M 1708-1-38, k. 5v.

Daskowicz / Daszkowicz: Иванъ Дашковичъ 1528 RIB 33, 182; Марекъ Дасковичъ 1567 RIB 33, 1099; Павелъ Дашковичъ Керсиновский 1567 RIB 33, 1100; Paulus olim Daskowicz 1569 AU 245; oll[im] Iwan Daszkowicz Kierznowski 1602 L 812-1-7, k. 72; Nobilis Alexandri 
Daskowicz Kiersnowski 1648 M 1708-1-37, k. 402; Nlium Alberti ol[im] Alexandri Basikowicz [!] Kierznowski 1649 M 1708-1-37, k. 1358; Nobiles Martinum oli[m] Alexandri Daszkoicz Kierznowski 1655 M 1708-1-39, k. 274; Młyn Kierznowo nazwany Daszkowsczyzna po Panu Woyciechu Kierznowskim Daszkiewiczu 1663 M 1708-1-43, k. 484

Gnatowicz / Ignatowicz: Еско Кгнатовичъ Путило 1528 RIB 33, 182; Олешко Игнатович 1528 RIB 33, 182; Васко Игнатович 1528 RIB 33, 182

Jeskowicz: Миско Есковичъ 1528 RIB 33, 182; Олешко Игнатович 1528 RIB 33, 182; Осташъ Есковичъ 1528 RIB 33, 182

Kalisiewicz: $N[0] b[i] l i b u s$ Dauid et Joanni filiis olim [...] Kalisewicz Kierznowski 1652 M 1708-1-38, k. 5v.

Klimowic: ol[im] N[obi]l[e]m Siemion Klimowic Abrahamowic Kierznowski 1668 M 17081-161, k. 413 v.

Markoicz / Markowic / Markowicz: Nobilis Clemens Markoicz Kierznowski 1630 M 17081-206, k. 121; Simonis Markowic 1663 M 1708-1-43, k.169; Slach Eustachy Markowicz 1674 ASK I 70, 422

Mienczukowicz: N[obi]les Gregorium Mienczukowicz Kiersnowski 1672 M 1708-1-49, k. 411 v.

Miskowicz: Калисъ Мисковичъ 1567 RIB 33, 110о; Иванъ Мисковичъ 1567 RIB 33, 1100; Iwan Miskowicz 1569 AU 245

Oleszkowicz: Hryc Oleszkowicz de Kiersnowo 1569 ZZG 18, s. 457

Ostapkowic: N[obi]les Petrum et Jacobum Kierznowskich Ostapkowicow 1651 M 1708-1-141, k. $491 \mathrm{v}$.

Ostaszewicz: Богданъ Осташевичъ 1567 RIB 33, 1099; Василъ Осташевичъ 1567 RIB 33, 1099

Paszkowicz: Daniel et Joannes filii olim Stephani Paszkowicz 1667 M 1708-1-161, k. 107 V.

Pawłowicz: Lewon, Bart[holo]maeus, Stephanus filii olim Bohdan Pawłowicz Kierznowski 1604 L 812-1-8, k. 1

Pucziłowicz / Pucziłow (syn): Анъдрей Пучиловичъ 1567 RIB 33, 1099; Вавърынецъ Пучиловъ сынъ 1567 RIB 33, 1099

Sobechowicz / Sobiechowic: Andreae Sobiechowic 1668 M 1708-1-161, k. 632; P. Pawet Sobechowicz 1692 KGB 52, 200

Waskowicz: Иванъ Васковичъ Керсиновский 1567 RIB 33, 1099; Костюкъ Васковичъ Керсиновский 1567 RIB 33, 1099; Миколай Васковичъ Керсиновский 1567 RIB 33, 1099; Стецъко Васковичъ Керсиновский 1567 RIB 33, 1099

Mniej jest onimów opartych na apelatywach. Wyekscerpowano 4 derywaty tego typu:

Kleskiewicz: Alberti Kierznowski Kleskiewicz 1672 M 1708-1-49, k. 313 v. 
Noskowicz: N[obi]lis Hryc Noskowicz de Kiersnowo 1588 ZZG 17, s. 510

Pienkowicz: Nobilium Josephi Mathai Pienkowicz [...] bonorum Kierznowo haeredum 1667 M 1708-1-161, k. 107 v.

Skoczkowicz: Joannes, Nicolaus oll[im] Iwan Skoczkowicz [...] de Kiersnowo h[ae]r[e]des 1608 L 812-1-8, k. 77 v.

Liczba przedstawionych poświadczeń wskazuje na znaczący udział formantu -ic(z), -(ow)ic(z), -(ew)ic(z) w procesie tworzenia dodatkowych określeń antroponimicznych XVI- i XVII-wiecznej szlachty podlaskiej, zwłaszcza tej pochodzenia ruskiego. Badania antroponimii tego terenu wskazują na jego dużą popularność, szczególnie w XVI wieku, również w innych warstwach społecznych: u chłopów i mieszczan (Tichoniuk 1988: 84-87, Citko 2001: 126-127). Nieco mniejszą grupę, liczącą 12 jednostek, stanowią derywaty antroponimiczne na -ik, -yk, -czyk. Udało się wyekscerpować następujące onimy tego rodzaju:

Formacje odimienne (10):

Andruscyk / Androsik: N[obi]lem Martinum filium olim Chwiedoris Andruscyk Kierznowski 1667 M 1708-1-45, k. 75; Slach[etny] Marcin Androsik 1674 ASK I 70, 422

Bartoszyk: Slach[etny] Daniel Bartoszyk 1674 ASK I 70, 422

Bohdanik: Nobili Petro filio olim no[bi]lis Stephani Bochdanik Kiersnowski 1665 M 1708-1158, k. 213

Filipik: Slach[etny] Dawid Philipik 1674 ASK I 70, 422; Slach[etny] Jan Philipik 1674 ASK I 70,422

Hieronimik / Jaromik / Jarosik / Jeronimik / Jaronimik: Slach[etny] Daniel Jaromik 1674 ASK I 70, 422; Nobilis Daniel filius n[obi]lis Stephani Jeronimik Kiersnowski 1651 M 1708-1-141, k. 634; Slach[etny] Jan Jaronimik 1674 ASK I 70, 422; Nobiles Joannes olim Stephani Hyeronimik Kierznowski 1668 M 1708-1-161, k. 450; Slach[etny] Symon Jarosik 1674 ASK I 70, 422

Konstanczyk / Kostiuszyk: Slach[etny] Pawet Kostiuszyk 1674 ASK I 70, 422; Szl[achetny] Paweł Konstanczyk 1676 BCz 1099, 828

Ostapik / Ostapczyk: No[bi]lem Jacobum Ostapik Kiersnowski 1649 M 1708-1-37, k. 784; Slach[etny] Piotr Ostapczyk 1674 ASK I 70, 422

Putylik: N[obi]les Joannem olim Petri Putylik Kierznowskim 1672 M 1708-1-49, k. 331

Sidorzyk: Nobilis Chwiedor Sidorzyk Kierznowski 1643 M 1708-1-134, k 396

Ustianik: Slach[etny] Marcin Ustianik 1674 ASK I 70, 422

Formacje odapelatywne (2):

Cecelik: No[bi]lis Andreas filius olim Theodori Kiersnowski Cecelik 1665 M 1708-1-158, k. 213

Przynoszyk: N[obi]lis Iwan oll[im] Laurentii Przynoszyk Kiersnowski 1593 ZZG 18, s. 225 
Można zauważyć, że wymienione formacje były popularne w XVII wieku. Pierwszy odnotowany zapis pochodzi dopiero z 1593 roku. Jeśli chodzi o deskrypcje zawierające inne formanty, dysponujemy 1 przykładem nazwy osobowej zakończonej na -ak: Klimunciak: Szl[achetny] Mikołay Klimunciak 1676 BCz 1099, 829, 2 poświadczeniami na -uk: Sawczuk: Slach[etny] Theodor Sawczuk 1674 ASK I 70, 422, Sobiesczuk: Slach[etny] Philip Sobiesczuk 1674 ASK I 70, 422, i 1 określeniem na -ski: Putyłowski: N[obi]lis Joski Putylowski de Kierstnowo 1544 ZZG 20, s. 72. Nie jest wykluczone, że ten ostatni antroponim mógł pełnić funkcję protonazwiska.

Niederywowane określenia członków rodu Kiersnowskich występują w przebadanym materiale antroponimicznym rzadziej. Wyekscerpowano 5 formacji odimiennych tego typu oraz 4 odapelatywne. Oto one:

Formacje odimienne (5):

Bohdan: N[obi]lis Petrus ol[im] Stephani Bohdan Kierznowski 1666 M 1708-1-158, k. 522

Daszko: Alexander oll[im] Danielis Daszko de Kierznowo 16o4 L 812-1-7, k. 126 v.; olim Nobilis Alexandro Daszko Kiersnowski 1674 M 1708-1-170, k. 117

Pacz: N[obi]lis Demian oll[im] Pauli Pacz Kiersnowki 1588 ZZG 17, s. 513

Putyło: Еско Кгнатовичъ Путило 1528 RIB 33, 182; Clemens oll[im] Laurentii Putyło Kierznowski in Kierznowo h[ae]r[e]s 1604 L 812-1-8, k. 1 v.; Nobil[es] Siemion et Klym Putyłowie Kierznowscy 1618 M 1708-1-31, k. 615; N[obi]lis Clemens Putiło Kierzsnowski [...] olim Benedicti 1630 M 1708-1-206, k. 121 v.; Petri Putyło Kierzsnowski 1630 M 17081-206, k. 121 v.; N[obi]les [...] Abrah[am]u[m] Putyło Kiersnowski 1639 M 1708-1-129, k. 499; N[obi]lem Clementem olim Abrahamis Kierznowski Putyło 1643 M 1708-1-134, k 150; n[obi]lem Petrum ol[im] Siemioni Putyło Kierznowski 1643 M 1708-1-134, k 232 v.; No[bi]lem Chwiedor ol[im] Stephani Putyło Kiersnowski 1649 M 1708-1-37, k. 1677; Petri Putyło 1663 M 1708-1-43, k.169; N[obi]li Joannis olim Petri Putyło Kiersnowski 1668 M 1708-1-161, k. 6oo; olim Demiani Putyło Kierznowski 1674 M 1708-1-170, k. 52; Slach[etny] Jan Kierznowski Putyło 1674 ASK I 70, 421

Tos / Tosz: N[obi]lis Thomasz Tosz Kierznowski 1593 ZZG 18, s. 230; N[obi]lis Joannes filius Thomae Tos Kierznowski 1597 ZZG 18, s. 281

Formacje odapelatywne (4):

Korszen: N[obi]lis Sidor filius Laurenti Korszen de Kierznowo 1569 ZZG 18, s. 460

Sokala: Dawid, Chwiedor et Ustian filii oll[im] Hrycz Sokala Kierznowski 1602 L 812-1-7, k. 57 v. Szyło: N[obi]lem Paulum Szyło Kiersnowski 1668 M 1708-1-161, k. 600

Tur: Iwan Thur 1569 AU 245 
Dodatkowym sposobem identyfikacji antroponimicznej kobiet z rodziny Kiersnowskich (oprócz omówionej już identyfikacji przy pomocy imienia) było użycie określenia dodatkowego utworzonego od imienia albo przezwiska/przydomka męża (formacji marytonimicznej). Nie odnotowano ani jednego przypadku zastosowania formacji patronimicznej, a więc odwołania się do onimu identyfikującego ojca. Zapewne wynika to ze specyfiki niektórych wykorzystanych źródeł, w których określenie dodatkowe przysługiwało tylko posiadaczom gruntu - wdowom (w spisach podatkowych) albo głowom rodzin (w rejestrach pogłównego). Inaczej wyglądało to w zapisach z ksiąg grodzkich, gdzie rolę elementów deskrypcyjnych pełniły określenia kobiet, jak już wspomniano, utworzone od imienia męża (11 przykładów) albo od jego przezwiska/przydomka (2 przykłady). Formacje te przedstawiają się następująco:

Formacje odimienne (11):

Danielowa: P. Danielowa Jaromikowa /unitka/ 1692 KGB 52, 200

Dawidowa: P. Dawidowa Kiersnowska syn Woyciech z żonq /unitka/ 1692 KGB 52, 200

Filipowa: P. Filipowa Kiersnowska /unitka/ 1692 KGB 52, 200

Grzegorzowa: Sz[lachetna] Grzegorzowa Kiersznowska /katoliczka/ 1692 KGB 52, 183 v.; Sz[lachetna] Grzegorowa Kiersznowska /katoliczka/ 1692 KGB 52, 183 v.

Iwanowa: Slach[etna] Iwanowa wdowa /unitka/ 1674 ASK I 70, 422

Jakubowa: Slach[etna] Jakubowa wdowa syn z żonq /unitka/ 1674 ASK I 70, 422

Janowa: P. Janowa Kiersnowska wdowa /unitka/ 1692 KGB 52, 200

Pawłowa: P. Pawłowa wdowa Kiersnowska /unitka/ 1692 KGB 52, 200

Piotrowa: P. Piotrowa Bohdanowa corka /unitka/ 1692 KGB 52, 200

Prokopowa: P. Prokopowa Kiersnowska /unitka/ 1692 KGB 52, 200

Stanisławowa: Sz[lachetna] Stanisławowa wdowa /katoliczka/ 1692 KGB 52, 183 v.

Formacje odprzezwiskowe/odprzydomkowe (2):

Bohdanowa: P. Piotrowa Bohdanowa corka /unitka/ 1692 KGB 52, 200

Jaromikowa: P. Danielowa Jaromikowa /unitka/ 1692 KGB 52, 200

Warto w tym miejscu podkreślić, że przytoczone określenia dodatkowe członków rodu Kiersnowskich, zarówno mężczyzn, jak i kobiet, zostały wyabstrahowane z materiału onomastycznego jako pewne potencjalne jednostki identyfikacji antroponimicznej. Należy zauważyć, że w praktyce jednostki te były elementami różnorakich modeli nominacji rzeczywistej, realizowanej w określonym czasie i miejscu.

Przedstawiona analiza nie wyczerpuje wszystkich aspektów omawianej tematyki, a tym samym, może być dodatkowo pogłębiona. Jednak zasygnalizowane tu problemy i zjawiska składają się na obraz przykładowego mikrosystemu antroponimicznego położonego 
na granicy etnosów: polskiego i wschodniosłowiańskiego. Trzeba odnotować, że na jego kształtowanie się, oprócz lingwistycznych, miały wpływ również czynniki kulturowe (religijno-konfesyjne), etniczne oraz społeczne. Właśnie z tej perspektywy należy patrzeć na rozwój i przekształcenia owego systemu.

\section{ANEKS}

Wywód szlachectwa Kiersnowskich, potwierdzający ich pochodzenie ze wsi Skoki w powiecie brzeskim oraz przynależność do rodu herbowego Cholewów.

AN w Krakowie, ZZG 18 (Zbiór Zygmunta Glogera, sygn. 18), s. 97-99.

[s. 97] 1586 Anno in Bransko Curia Regali, Feria 6ta in wigilia Festi Sa Luciae

Kiersnowo Literae Testimonii

[s. 98] Szlachetni Mikołay Syn Nieboszczyka Wawrzyńca Bieniasz Łukasz Nieboszczyka Stefana Synowie, Iwan przeszłego Pawła z Kierznowa Powiatu tutecznego Bielskiego Dziedzice zeznali y Protokut swego Pokolenia y Szlachectwa powiedzieli, iż za Panowania Świętey Pamięci Krola Alexandra Przodkow ich Kiersnowskich, było trzey Braciey Rodzonych Ihnat, Jessyo Bohdan którzy mieli dwoie Imienie Oyczyste nierozdzielne Kiersnowo w Bielskim, a Skoki w Brzeskiem Powiecie leżące, Herbu Cholewicza, które Imiona potym miedzy sobą rozdzielili, to iest Kierznowo w Bielskiem Powiecie Ihnat i Jessiu, a Skoki, w Brzeskim Powiecie WoXaLo Bohdan, którego było przezwano Kłoywoda wzieli i czasy wiecznemi Między sobq Rozdzielili, który Bohdan tam Mieszkaiąc na Skokach w Xsięstwie Litewskim spłodził Syna Siemiona, a potym Siemion spłodził Synow Bohdana Fiedora, Piotra, Łukasza, z których Bohdan umart, a iż ieden z tych Synow Siemionowych Szlachetny Fiedor Kierznowski, który tam na tym Imieniu Skokach po przodkach Swoich z wsza Bracią Mieszka, Brat tych Kiersnowskich z Dziada Praciada, z Oyca Herbu pomienionego, dla Ostrozności i pilnieyszey Opatrzności [s. 99] Spraw i rzeczy swych teraznieyszych i potem przypadtych i przyszłych, prosit, i używat ich wtem aby Oni z powinności swey Jego Szlachetnego Narodu być przyznali [...] Którzy pod przysięga zeznali, iż pomieniony Fiedor Kiersnowski z Skokow Syn Nieboszczyka Siemiona iest ich z wyżey mianowanych i napisanych Przodkow Brat Herbu pomienionego Cholewicza. 
SKRÓTY NAZW WYKORZYSTANYCH ŹRÓDEŁ

drukowanych:

AU, Spis szlachty składającej przysięgę Koronie Polskiej w 1569 r., Akta Unii Polski z Litwa 1385-1791, wyd.

S. Kutrzeba, W. Semkowicz, Kraków 1932, s. 236-264.

HerKap, I. Kapica Milewski, Herbarz, Kraków 1870.

RIB 33, Popis wojenny ziemi bielskiej z 1528 r. i powiatu bielskiego z 1567 r., Russkaja Istoriczeskaja

Biblioteka, t. 33, szp. 124-182; szp. 1035-1182.

ŹDz 17, Rejestr poborowy woj. podlaskiego z 1580 r. Źródła dziejowe, t. 6, wyd A. Jabłonowski , t. 17,

Warszawa 1908, s. 90-128.

rękopiśmiennych:

AGAD w Warszawie:

ASK I 70, Rejestr pogłównego pow. brańskiego z 1674 r., k. 382-453 v.

KGB 52, Księga grodzka brańska z 1692 i 1712 r.

BN w Warszawie:

BCz 1099, Rejestr poborowy ziemi bielskiej z 1676 r., s. 791-846

CDIAU we Lwowie:

L 812-1-7, Regesty dokumentów z ksiąg grodzkich brańskich z 1. 1600-1604

L 812-1-8, Regesty dokumentów z ksiąg grodzkich brańskich z 1. 1604-16o8

NGAB w Mińsku:

M 1708-1-4, Księga grodzka brańska z 1. 1562-1563

M 1708-1-31, Księga grodzka brańska z l. 1617-1618

M 1708-1-35, Księga grodzka brańska z 1. 1625-1626

M 1708-1-37, Księga grodzka brańska z 1. 1648-1649

M 1708-1-38, Księga grodzka brańska z 1652 r.

M 1708-1-39, Księga grodzka brańska z 1655 r.

M 1708-1-41, Księga grodzka brańska z l. 1661-1663

M 1708-1-43, Księga grodzka brańska z 1663 r.

M 1708-1-45, Księga grodzka brańska z 1667 r.

M 1708-1-49, Księga grodzka brańska z 1. 1672-1673

M 1708-1-51, Księga grodzka brańska z 1678 r.

M 1708-1-57, Księga grodzka brańska z 1690 r.

M 1708-1-84, Księga grodzka brańska z 1599 r.

M 1708-1-91, Księga grodzka brańska z 1601 r.

M 17o8-1-98, Księga grodzka brańska z l. 1607-16o8

M 1708-1-109, Księga grodzka brańska z l. 1621- 1625

M 1708-1-129, Księga grodzka brańska z 1639 r.

M 1708-1-133, Księga grodzka brańska z 1643 r. 
M 1708-1-134, Księga grodzka brańska z 1643 r.

M 1708-1-141, Księga grodzka brańska z 1. 1650-1651

M 1708-1-153, Księga grodzka brańska z 1. 1661-1662

M 1708-1-158, Księga grodzka brańska z 1. 1665-1666

M 1708-1-159, Księga grodzka brańska z 1665 r.

M 1708-1-161, Księga grodzka brańska z l. 1667-1668

M 1708-1-169, Księga grodzka brańska z 1. 1672-1673

M 1708-1-170, Księga grodzka brańska z 1674 r.

M 1708-1-172, Księga grodzka brańska z 1676 r.

M 1708-1-182, Księga grodzka brańska z 1685 r.

M 1708-1-196, Księga grodzka brańska z 1695 r.

M 1708-1-206, Księga grodzka brańska z 1630 r.

AN w Krakowie:

Zbiór Zygmunta Glogera

ZZG 17, Odpisy dokumentów z ksiąg relacji i dekretów grodzkich brańskich z 1. 1541-1599

ZZG 18, Odpisy dokumentów z ksiąg relacji i dekretów grodzkich brańskich z 1. 1537-1599

ZZG 20, Odpisy dokumentów z ksiąg grodzkich brańskich: relacji, dekretów, ksiąg wieczystych z l.

1537-1791

\section{BIBLIOGRAFIA}

Citko 20o1: Citko, Lilia. Personal Names of the Northern Podlasie ( $16^{\text {th }}$ Century). University of Bialystok Press, 2001. [In Polish: Citko, Lilia. Nazewnictwo osobowe pótnocnego Podlasia w XVI w. Białystok: Uniwersytet w Białymstoku, 2001.]

Kondratiuk 1974: Kondratiuk, Michał. Place Names of the South-Eastern Bialystok Region.

Wroclaw: ZNiO, 1974. [In Polish: Kondratiuk, Michał. Nazwy miejscowe południowo-wschodniej Białostocczyzny. Wrocław: Zakład Narodowy im. Ossolińskich, 1974.]

Malec 1994: Malec, Maria. Christian Names in Medieval Poland. Krakow: PAN, 1994. [In Polish: Malec, Maria. Imiona chrześcijańskie w średniowiecznej Polsce. Kraków: PAN. Instytut Języka Polskiego, 1994.]

Romaniuk 1993: Romaniuk, Zbigniew. „Cerkiew unicka w Bransku.” Ziemia Branska, no 4 (1993): 23-33. [In Polish: Romaniuk, Zbigniew. „Cerkiew unicka w Brańsku.” Ziemia Brańska, nr 4 (1993): 23-33.]

Tichoniuk 1986: Tichoniuk, Bazyli. Odapelatywne nazwy terenowe poludniowej Bialostocczyzny. Slownik topoosnow. Opole: Wyzsza Szkola Pedagogiczna in. Powstancow Slaskich, 1986. [In Polish: Tichoniuk, Bazyli. Odapelatywne nazwy terenowe południowej Białostocczyzny. Słownik topoosnów. Opole: Wyższa Szkoła Pedagogiczna in. Powstańców Śląskich, 1986.] 
Tichoniuk 1988: Tichoniuk, Bazyli. Antroponimia poludniowej Bialostocczyzny w XVI w. Opole: Wyzsza Szkola Pedagogiczna, 1988. [In Polish: Tichoniuk, Bazyli. Antroponimia południowej Białostocczyzny w XVI w. Opole: Wyższa Szkoła Pedagogiczna, 1988.]

Tichoniuk 2ooo: Tichoniuk, Bazyli. Imiona i ich formy na pograniczu polsko-bialoruskim od XVI wieku do roku 1839. Zielona Gora: Wyzsza Szkola Pedagogiczna im. Tadeusza Kotarbinskiego, 2000. [In Polish: Tichoniuk, Bazyli. Imiona i ich formy na pograniczu polsko-biatoruskim od XVI wieku do roku 1839, Zielona Góra: Wyższa Szkoła Pedagogiczna im. Tadeusza Kotarbińskiego, 20oo.]

Wisniewski 1964: Wisniewski, Jerzy. „Rozwoj osadnictwa na pograniczu polsko-rusko-litewskim od konca XIV do polowy XVII w." Acta Baltico-Slavica, no 1 (1964): 115-135. [In Polish: Wiśniewski, Jerzy. „Rozwój osadnictwa na pograniczu polsko-rusko-litewskim od końca XIV do połowy XVII w.” Acta Baltico-Slavica, $\mathrm{nr} 1$ (1964): 115-135.]

Wisniewski 1977: Wisniewski, Jerzy. „Eastern Region of Bialystok District Colonization -Genetics, Development, Differentiation and Ethnic Changes.” Acta Baltico-Slavica, no 11 (1977): 7-80. [In Polish: Wiśniewski, Jerzy. „Osadnictwo wschodniej Białostocczyzny - geneza, rozwój oraz zróżnicowanie i przemiany etniczne." Acta Baltico-Slavica, nr 11 (1977): 7-80.]

Zlotkowski 2017a: Zlotkowski, Piotr. The Historical Anthroponomy of Burghers and Peasants of Bransk and the Area Around as Analized from the Static and Dynamic Point of View. Lublin: UMCS University Press, 2017. [In Polish: Złotkowski, Piotr. Antroponimia historyczna mieszczan i chtopów Brańska i okolic w ujęciu statycznym i dynamicznym. Lublin: Wydawnictwo UMCS, 2017.]

Zlotkowski 2017b: Zlotkowski, Piotr. „Podlachian House of Poletylo in the Light of Anthroponymy (16-17 $7^{\text {th }}$ Centuries)." Annales Universitatis Mariae Curie-Sklodowska, sec. FF Philologiae, no 35, vol. 2 (2017): 179-192. [In Polish: Złotkowski, Piotr. „Podlaski ród Poletyłów w świetle antroponimii (XVI-XVII wiek)." Annales Universitatis Mariae Curie-Skłodowska, sec. FF Philologiae, nr 35 , z. 2 (2017): 179-192.] 